\title{
The size of wild honeybee populations (Apis mellifera) and its implications for the conservation of honeybees
}

\section{Robin F. A. Moritz ${ }^{1,4}$, F. Bernhard Kraus ${ }^{2}$, Per Kryger ${ }^{3,4}$ and Robin M. Crewe ${ }^{4}$}

1. Institut für Biologie, Martin Luther Universität Halle-Wittenberg, Hoher Weg 4, D 06099 Halle/Saale, Germany

2. Departamento Entomología Tropical, El Colegio de la Frontera Sur, Carretera Antiguo Aeropuerto Km. 2.5, C. P. 30700 Tapachula, Chiapas, Mexico

3. Department of Crop Protection, Research Centre Flakkebjerg, Danish Institute of Agricultural Sciences, 4200 Slagelse, Denmark

4. Department of Zoology and Entomology, University of Pretoria, 0002 Pretoria, South Africa

\section{Abstract}

The density of wild honeybee colonies (Apis mellifera) in the African dry highland savannahs was estimated in three Nature Reserves in Gauteng, South Africa (Ezemvelo, Leeuwfontein, Suikerbosrand) based on the genotypes of drones which were caught at drone congregation areas. Densities were estimated to range between 12.4 and 17.6 colonies per square kilometer. In addition colony densities were estimated in two German National parks (Müritz and Hochharz) and a commercial mating apiary. The density of colonies was significantly lower at the German sampling sites with estimates of 2.4-3.2 colonies per square kilometer, which closely matches the nation-wide density of colonies kept by beekeepers. This shows that the densities of colonies observed in wild populations under the harsh conditions of the African dry savannahs exceeds that of Germany by far, in spite of intensive beekeeping. The intensity of apiculture in Europe is therefore unlikely to compensate for the loss of habitats suitable for wild honeybees due to agriculture, forestry and other cultivation of land. 


\section{Introduction}

The western honeybee, Apis mellifera, is an important element in sustainable agriculture since it provides the colony products of wax and honey, and by its pollination service. Since the beginnings of human culture the honeybee and its products have been of great value to man, which is why apiculture is deeply rooted in many human cultures. In addition, however, the honeybee is also a wild animal which is endemic to Europe, the near East and Africa, with over 20 subspecies and ecotypes in numerous ecosystems (Ruttner 1988). Wild populations, uninfluenced by beekeepers, exist in many regions of Africa where apiculture is poorly developed and honey is harvested by means of traditional honey hunting. Many efforts have been made to establish beekeeping globally, resulting in the transport of Apis mellifera to new continents. The western honeybee has now successfully established feral populations in the Americas and Australia.

This spread of honeybees has been viewed with mixed feelings. The impact of apiculture and the density of managed honeybee colonies on other pollinators has been regarded as deleterious from the point of view of nature conservation (Roubik 1978). Indeed, the honeybee is a generalist with a well developed communication system with the ability to recruit large numbers of workers to rewarding food sources. They should be able to easily outcompete other pollinators. However, the evidence for such competition is not compelling (Roubik and Wolda 2001; Moritz et al. 2005) and factors other than honeybees seem to have had a much more dramatic impact on global pollinator declines (Roubik 2000; Kevan and Philips 2001).

Although the discussion about the potential competition between managed honeybee colonies and wild pollinators is interesting, one essential piece of evidence on this topic is rarely addressed: the density of A. mellifera colonies in the wild. The endemic wild honeybee populations are most often forgotten in the debate about the impact of apiculture on wild pollinators and unfortunately many authors do not even refer to honeybees when dealing with wild bees. Clearly, we would expect the strongest competition to be between wild and managed honeybee colonies and indeed all well 
documented examples of honeybee invasions are about the competition within the genus Apis (Moritz et al. 2005).

One important point when debating the impact of beekeeping on biodiversity is therefore the density of wild honeybee colonies in relation to the managed population. Only if we know how many honeybee colonies can be sustained in natural habitats can we address this issue from a conservation perspective. Although there is some evidence on the density of feral honeybee colonies (Schneider et al. 2004; Oldroyd et al. 1997) reliable density estimates in endemic wild populations are lacking. This is not surprising, because wild A. mellifera colonies are usually extremely cryptic and hard to detect. They nest in rock crevices, caves, hollow trees or earth cavities (Seeley 1985). Determining the number of wild colonies by spotting the location of nests is therefore a difficult task at best, since it may only poorly reflect the actual population sizes. Moreover, the area covered by a population of A. mellifera can be extremely large. The mating range of queens and drones can exceed $80 \mathrm{~km}^{2}$ (Ruttner and Ruttner 1972), an area far too large to reliably searched for honeybee colonies.

With the advance of DNA technologies, it has become possible to estimate the effective population size from genotype data (Estoup et al. 1994). This technique has its own limitations. It is easy to sample foraging workers at flowers in the field. However, analysis of samples taken in this manner can yield highly biased samples because workers recruit nestmates to food sources (von Frisch 1967). The workers sampled at the same site therefore may originate from a single or a few colonies only and may not represent a random population sample. This will cause serious underestimates of the population size. Even given that worker samples in the field yield a random population sample, it is virtually impossible to infer the number of mother colonies from the workers' genotypes because of the high level of multiple mating of the queen. Workers from the same colonies often belong to different halfsib families and thus only share a maternal but not a paternal allele (Moritz and Southwick 1992). 
A better picture of the number of reproductive colonies in a population can be obtained by sampling drones. This is easy if there is access to managed apiaries. Samples of worker brood can be taken from the colonies and the genotypes of siring drones can be inferred from the queen's female offspring (Estoup et al. 1994; Neumann et al. 1999; Kraus et al. 2003, 2004). However in the wild this is often impossible, because the colonies are hard to find and the large number of undetected colonies yield incomplete results. Also commercial apiaries may only poorly reflect the density of wild honeybee colonies in any given area. One alternative is to place small mating colonies with unmated queens into the region of interest. After these queens have been mated, their worker offspring can be genotyped to infer the genotypes of the drones from the surrounding population the queens have mated with. However, this procedure is not always feasible, because it entails a well established apicultural infrastructure. It requires the establishment of a sampling apiary at a secure and undisturbed site to place the mating colonies. Well established queen rearing facilities are needed to produce the virgin queens. Mating colonies have to be created and must be transported to the site where sampling is to take place. Repeated site visits are necessary to check the mating colonies and take brood samples within a 3-week interval after mating. Alternatively, it is possible to sample drones directly during their mating flights. Since drones from dispersed colonies covering a large region aggregate for mating at so called drone congregation areas (DCA, Ruttner and Ruttner 1972) sampling is expected to be relatively unbiased. This technique was first introduced by Baudry et al. (1998). They estimated more then 200 colonies in a region with high density apiculture, when trapping drones with a trap designed by Williams (1987). In this study, depending on the development of apiculture in the sampling region, we used both approaches to determine colony densities and genetic diversity in wild and human influenced populations of $A$. mellifera. The sampling of drones with a pheromone trap was used in three nature reserves of the African Highveld (South Africa) for wild populations of A. mellifera scutellata, which are uninfluenced by apicultural activities. The sampling of drones via virgin queens was used in Germany for populations of A. mellifera carnica in two national parks and in one area around a commercial mating apiary. Both sampling techniques have the advantage that they only include colonies that produce male sexuals 
and hence only those which actively contribute to the gene pool. Although drone genotypes are determined in both procedures, it must be noted that the sampling areas are different in two methods. Trapping drones at a drone congregation area only samples drones within the flight range of drones. Sampling drone genotypes through mated queens covers a larger sampling area including the flight range of both queens and drones.

\section{Materials and methods}

\section{Sampling in South Africa}

In South Africa we used the drone sampling technique, because African honeybee colonies have a high tendency to abscond particularly if disturbed by transport and provided with virgin queens.

About 100 drones each were sampled at DCAs in three different nature reserves (Leeuwfontein $n=96$, Suikerbosrand. $n=127$; Ezemvelo $n=96$ ) in Gauteng (Republic of South Africa) in February 2004 (Fig. 1A). The drones were caught after 16:00 local time under sunny $\left(>25^{\circ} \mathrm{C}\right)$ and windless conditions by raising a drone trap attached to a weather balloon up to $20 \mathrm{~m}$ (see Williams 1987 for details). As soon as about 20 drones had entered the trap, it was taken down and the drones were transferred into vials filled with ethanol (99\%) and stored at $-20^{\circ} \mathrm{C}$ until DNA processing.

A

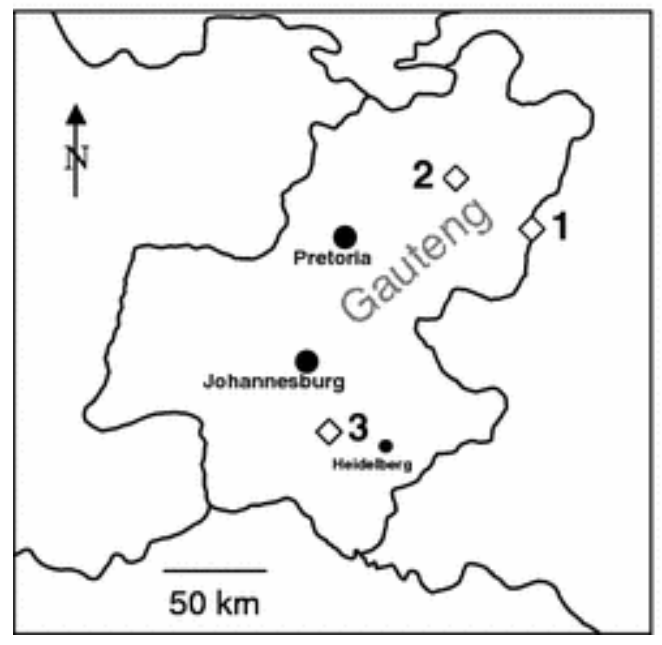

B

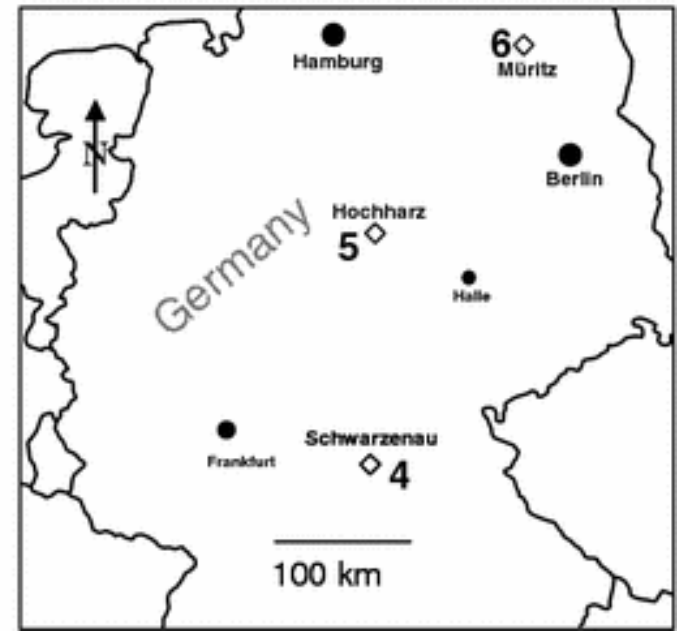


Fig. 1 (A) Sampling sites in South Africa in the province of Gauteng: Ezemvelo (1), Leeuwfontein (2) and Suikerbosrand (3). (B) Sampling sites in Germany: Schwarzenau (4), Hochharz (5) and Müritz (6)

\section{Sampling in Germany}

The indirect sampling of drone genotypes via virgin queens was conducted in three different locations in Germany, two national parks and one mating apiary in a rural area in Bavaria in the year 2001 (Fig. 1B). The virgin queens (A. m. carnica), which were mated in the national parks (Mueritz National Park: 8 queens; Hochharz National Park: 7 queens), were kept in small "nucleus" mating boxes containing 2,000 worker bees and no drones. These mating boxes were placed on selected sites in the center of the national parks during the mating season. After a 2-week period, the queens had successfully mated and had started egg laying. This diploid worker brood was collected and stored in $99 \%$ Ethanol at $-20^{\circ} \mathrm{C}$ until DNA processing. At the mating apiary Schwarzenau, we sampled worker brood directly from the colonies of queens, which were mated there for breeding purposes in the season of 2001 (5 queens). These samples also were stored in $99 \%$ Ethanol at $-20^{\circ} \mathrm{C}$ until DNA processing.

\section{DNA analyses}

DNA was extracted using routine methods (Walsh et al. 1991) and genotyped with one of two primer sets containing either A7, A14, A28, A76, A79, A88, A107, A113, A24, Ap43 (set 1) for the German populations or A7, A14, A28, A76, A79, A88, A107, A113, A35, B124 (set 2) for the South African populations (Estoup et al. 1994; Solignac et al. 2003) using an ABI 310 sequencer. The genotypes of the directly sampled (Africa) or inferred (Germany) drones were prepared with standard spreadsheet software (EXCEL Microsoft ${ }^{\circledR}$ ) using the Excel Microsatellite Toolkit by Park (2001). The unbiased gene diversity (expected heterozygosity; Nei 1987) was calculated from the drone allele frequencies for the six subpopulations as well as for the African and German populations as a whole. Further we calculated overall and pairwise $F$ st values using the allele frequency based method of Weir and Cockerham (1984) and a Fisher's Exact test for population differentiation (Raymond and Rousseau 1995a) both implemented in Genepop 
(Raymond and Rousseau 1995b). We used the maximum likelihood method of COLONY (Wang 2004) to estimate the number of colonies from which the drones originated.

\section{Results}

\section{Gene diversity and population differentiation}

Table 1 shows the unbiased gene diversity (expected heterozygosity) in the studied populations in Germany and South Africa. The number of alleles per locus in the African populations was high with an average of $16.6 \pm 1.7$ alleles per locus. When fused and analyzed as a single population, the average number of alleles was as high as $33.9 \pm 15.5$ alleles per locus. In contrast the mean number of alleles in the German populations was much lower with an average of $8.24 \pm 1.29$ alleles per locus. When combined and analyzed as a single population, the average number of alleles per locus is only $11.9 \pm 16.1$ alleles per locus in Germany, which is significantly smaller than in the South African populations (Mann-Whitney $U$-test; $P<0.0001$ ). However, significant differences in the number of alleles were not found among the three populations of South Africa nor among the three German populations.

Table 1 Expected average heterozygosity over all loci in the six populations sampled and the heterozygosity in the pooled populations (total) in Germany and South Africa

\begin{tabular}{|l|l|l|l|l|}
\hline & $\begin{array}{l}\text { Number of } \\
\text { alleles }\end{array}$ & H exp & $\begin{array}{l}\text { n colonies } \\
\text { (observed) }\end{array}$ & $\begin{array}{l}\text { n colonies } \\
\text { (estimated) }\end{array}$ \\
\hline Leeuwfontein & $15.1 \pm 3.3$ & 0.881 & 32 & 34 \\
\hline Suikerbosrand & $16.3 \pm 4.5$ & 0.767 & 43 & 44 \\
\hline Ezemvelo & $18.4 \pm 4.7$ & 0.905 & 44 & 53 \\
\hline Total & $33.9 \pm 15.5$ & 0.905 & 119 & 131 \\
\hline Mean \pm SD & $16.6 \pm 1.7$ & $0.851 \pm 0.074$ & $39.7 \pm 6.7$ & $43.7 \pm 9.5$ \\
\hline Schwarzenau & $7.0 \pm 5.0$ & 0.666 & 27 & 28 \\
\hline Hochharz & $8.1 \pm 7.4$ & 0.680 & 23 & 24 \\
\hline Müritz & $9.6 \pm 10.4$ & 0.713 & 31 & 32 \\
\hline Total & $11.9 \pm 16.1$ & 0.675 & 79 & 84 \\
\hline Mean \pm SD & $8.2 \pm 1.3$ & $0.686 \pm 0.049$ & $27.0 \pm 4.0$ & $28.0 \pm 4.0$ \\
\hline
\end{tabular}


The degree of unbiased gene diversity was high in the three African populations ranging from 0.767 to 0.905 , as expected from the high number of alleles per locus.

Correspondingly the unbiased gene diversity in the German population was lower with values between 0.666 and 0.713 .

The pairwise Fisher's exact test for population differentiation indicated significant population differentiation $(P<0.0001)$ between the three African as well as between the three German populations, even after applying the Bonferroni adjustment for multiple tests. Nevertheless, we detected differences in population sub-differentiation and in the amount of gene flow between the African and German subpopulations (Table 2). The overall $F_{\text {st }}$ value for the African populations was 0.105 and for the German populations 0.064, indicating a more restricted gene flow among the African subpopulations although they were geographically much closer to each other (see maps in Fig. 1).

Table 2 Pairwise $F$ st values of the target populations in South Africa and Germany

\begin{tabular}{|l|l|l|l|l|l|}
\hline South Africa & \multicolumn{5}{|l|}{ Germany } \\
\hline Population & Leeuw-fontein & Suikerbos-rand & Population & Schwarzenau & Hochharz \\
\hline Suikerbos-rand & 0.126 & - & Hochharz & 0.064 & - \\
\hline Ezemvelo & 0.066 & 0.109 & Müritz & 0.061 & 0.057 \\
\hline
\end{tabular}

\section{Number of colonies}

The number of colonies in the subpopulations was inferred with COLONY (results shown in Table 1). The numbers of colonies in the three sample locations in South Africa ranged between 32 and 44, whereas the estimated number of colonies for the three German populations ranged between 23 and 31 . These numbers were corrected for the sample size according to Cornuet and Aries (1980) yielding estimates of 34-53 (mean $43.7 \pm 9.5$ ) colonies for the South African and 24-32 (mean 28.0 \pm 4.0 ) for the German populations. Thus the number of colonies estimated for the German populations was significantly smaller than in the South African populations (Mann-Whitney $U$-test; 
$P=0.049)$ although it was sampled with a method covering a larger sampling area than the African samples.

\section{Discussion}

In all locations we were able to sample a sufficiently large set of drones to estimate the number of colonies. Given males can fly up to $5 \mathrm{~km}$ per mating flight (Ruttner and Ruttner 1966; Ruttner 1966), the sampling area could be up to $80 \mathrm{~km}^{2}$. However, to infer the population density from the number of colonies represented at a drone congregation area, it seems more meaningful to base estimates on the average rather than the maximum flight distance of drones. Taylor and Rowell (1987) report $900 \mathrm{~m}$ as the mean flight distance, which results in an area of $2.5 \mathrm{~km}^{2}$ from which we may have recruited drones. This yields a density of 12.4-17.6 colonies per square kilometer for the African populations, much higher than previous estimates (2-9 colonies) based on counts of detected colonies in the Okavango swamps (McNally and Schneider 1996). However, Hepburn and Radloff (1998) explicitly address the problems of colony counts for assessing density of honeybee populations. The critical question is, what is the reference area when estimating the density? Our estimates assume that colonies are evenly distributed in the habitat, which seems highly unrealistic in light of the vast areas of very unattractive landscape for honeybees in both sampling areas. Whereas the African Highveld is largely characterized by a steppe grassland landscape, the German landscapes are characterized by vast regions of monoculture forestry and agriculture. Honeybee colonies are known to have highly patchy distributions in space and time (Oldroyd et al. 1997). Colonies may form migratory swarms that follow honey flows or abscond to escape diseases and infestations by parasites. The drone congregation areas we sampled were all located in the vicinity of creeks or rivers locally providing a rich flora and rewarding nectar sources in the otherwise meagre Highveld vegetation. It is therefore more likely that we attracted drones from a much smaller region limited by landscape and vegetation constraints in the local settings. The density of African honeybees may therefore have been locally much higher then assumed above due to the restricted and fragmented nesting site opportunities and local foraging potential. 
The drones in Germany were sampled with a different technique than the African samples, which has consequences for estimating the density of colonies. In the German experiments, virgin queens flew out to "sample" drones through multiple matings. Queens are known to fly to different drone congregation areas on their mating flights. They usually fly further than the drones on their mating flights (Ruttner and Ruttner 1972) to more distant DCAs (Koeniger et al. 2005). If we conservatively assume that queens fly as far as drones, the sampling radius will be on average at least twice as far compared to the procedure where drones are sampled on a single DCA site $\left(10.0 \mathrm{~km}^{2}\right.$ instead of $2.5 \mathrm{~km}^{2}$ ). Based on these assumptions the density of colonies is estimate to be 2.4-3.2 colonies per $\mathrm{km}^{2}$, which is almost an order of magnitude less than that observed in the African savannah.

The number of colonies registered to beekeepers in Germany is about 700,000 hives. Given a total area of $357,000 \mathrm{~km}^{2}$ for the Federal Republic of Germany (Statistisches Bundesamt Deutschland 2005) this yields a density of about two hives per $\mathrm{km}^{2}$, remarkably close to the estimates derived from our data. This suggests that most of the colonies sampled in the National Parks were probably derived from beekeepers apiaries. Even in a region with dense beekeeping (Schwarzenau) the number of colonies providing drones was much smaller when compared with the numbers observed in the Highveld. Although African drones are said to outcompete European drones in direct competition, European and African drones (Harrison et al. 2005), show similar flight times and flight durations (Hepburn and Radloff 1998). If flight ranges are similar, colony densities in the savannahs of the African Highveld are significantly higher and could be up to an order of magnitude higher than in near natural conditions of European National Parks. Even in regions with intensive beekeeping, colony densities were below the level observed in the not particularly favorable conditions of the African savannah.

Two non-exclusive scenarios might explain this difference between African and European honeybee populations.

(1) European populations typically have a much smaller number of colonies compared with African honeybees. It is well known that African honeybees establish 
smaller colonies with a higher propensity for reproductive swarming than European honeybees (Hepburn and Radloff 1998). On the one hand, this may be an adaptation of European honeybees to phases of long lasting winter, which require large honey stores and large colonies for survival. On the other hand this is also partly true for African honeybees which need to cope with extended periods of dearth during the dry winter phases and average minimum temperatures in winter as low as $3^{\circ} \mathrm{C}$ (July, Pretoria).

(2) European honeybee populations are smaller than African honeybee populations due to interference by man. The main difference between African and European habitats is that Europe has little if any natural habitats which, in contrast, are the predominant habitat types in the South African Highveld. Large scale habitat disturbance, primarily through agriculture and forestry monoculture, have depleted most European landscapes of natural ecosystems. Habitat destruction is thought to be the main driver of pollinator decline in Europe (Biesmeijer et al. 2006). Indeed managed forests, pastures and wheat fields make natural nesting sites for honeybees rare (e.g. hollow trees, ground cavities). We do not know what the historic population densities of wild honeybee populations in Europe was. However, given the climatic conditions one might expect that foraging conditions and nest site availability in a European deciduous forest with ample rainfall should be better and not worse when compared with a dry Highland savannah.

Currently we cannot exclude the possibility that European honeybee populations were at least similar in size to African populations before man embarked on the large scale destruction of natural habitats in Europe. From this perspective the current low population sizes are alarming in that the beekeeping activities by man and the managed honeybee population may not compensate for the loss of wild honeybee colonies. In addition, those colonies which were detected showed significantly less genetic variability compared with the wild populations, which may be due to selective breeding and the widespread propagation of selected stock by beekeepers. Clearly the continuing decline of beekeeping in Western and Central Europe does not help to ameliorate the situation. Also diseases may have contributed to a decline in honeybee colony density. For example the parasitic mite Varroa destructor almost eradicated the feral honeybee population in 
California a few years after its introduction (Kraus and Page 1995). Given these results it seems surprising that in many European countries almost all Apoidea are listed in the so called national red list. In sharp contrast, the honeybee Apis mellifera is often seen as an invasive species, merely having escaped from beekeeping operations rather than being recognized as an important and natural part of the local fauna and biodiversity. Our data suggest that there is very little reason not to protect honeybee populations and we suggest a serious reconsideration of its conservation status. It also demonstrates that beekeeping is not only a beneficial activity for producing honey and ensuring pollination services to wild and agricultural flora, but that it is an essential element for biodiversity conservation to maintain the density of honeybee colonies at a level comparable to that observed in the wild.

\section{References}

Baudry E, Solignac M, Garnery L et al (1998) Relatedness among honeybees (Apis mellifera) of a drone congregation. Proc R Soc Lond B 26:2009-2014

Biesmeijer JC, Roberts SPM, Reemer M et al (2006) Parallel declines in pollinators and insect-pollinated plants in Britain and the Netherlands. Science 313:351-354

Cornuet JM, Aries F (1980) Number of sex alleles in a sample of honeybee colonies. Apidologie 11:87-93

Estoup A, Solignac M, Cornuet JM (1994) Precise assessment of the number of patrilines and of genetic relatedness in honeybee colonies. Proc R Soc Lond B 258:1-7

von Frisch K (1967) The dance language and orientation of bees. Belknap Press of Harvard University Press, Cambridge MA

Harrison JF, Taylor OR, Hall HG (2005) The flight physiology of reproductives of Africanized, European, and hybrid honeybees (Apis mellifera). Physiol Biochem Zool 78:153-162 
Hepburn HR, Radloff SE (1998) Honeybees of Africa. Springer, Berlin, Heidelberg, New York

Kevan PG, Phillips TP (2001) The economic impacts of pollinator declines: an approach to assessing the consequences. Conserv Ecol 5:8

Koeniger N, Koeniger G, Pechhacker H (2005) The nearer the better? Drones (Apis mellifera) prefer nearer drone congregation areas. Insect Soc 52:31-35

Kraus B, Page RE (1995) Effect of Varroa jacobsoni (Mesostigmata: Varroidae) on feral Apis mellifera (Hymenoptera: Apidae) in California. Environ Entomol 24:1473-1480

Kraus FB, Neumann P, Scharpenberg H et al (2003) Male mating success of honeybee colonies (Apis mellifera L.). J Evol Biol 16:903-913

Kraus FB, Neumann P, van Praagh J, Moritz RFA (2004) Sperm limitation and the evolution of extreme polyandry in honeybees (Apis mellifera L.). Behav Ecol Sociobiol $55: 494-501$

McNally LC, Schneider SS (1996) Spatial distribution and nesting biology of colonies of the African honeybee Apis mellifera scutellata (Hymenoptera: Apidae) in Botswana, Africa. Environ Entomol 25:643-652

Moritz RFA, Southwick EE (1992) Bees as superorganisms - an evolutionary reality. Springer Verlag, Berlin, Heidelberg, New York

Moritz RFA, Härtel S, Neumann P (2005) The western honeybee (Apis mellifera L.): an invasive species? Ecoscience 12:289-301

Nei M (1987) Molecular evolutionary genetics. Columbia University Press, New York 
Neumann P, van Praagh JP, Moritz RFA, Dustmann JH (1999) Testing the reliability of a potential island mating apiary using DNA microsatellites. Apidologie 30:257-276

Oldroyd BP, Thexton EG, Lawler SH, Crozier RH (1997) Population demography of Australian feral bees (Apis mellifera). Oecologia 111:381-387

Park SDE (2001) Trypanotolerance in West African Cattle and the population genetic effects of selection. Dissertation, University of Dublin

Raymond M, Rousset F (1995a) An exact test for population differentiation. Evolution 49:1280-1283

Raymond M, Rousset F (1995b) GENEPOP (version 1.2): population genetics software for exact tests and ecumenicism. J Heredity 86:248-249

Roubik DW (1978) Competitive interactions between neotropical pollinators and Africanized honeybees. Science 201:1030-1032

Roubik DW (2000) Pollination system stability in tropical America. Conserv Biol $14: 1235-1236$

Roubik DW, Wolda H (2001) Do competing honey bees matter? Dynamics and abundance of native bees before and after honey bee invasion. Popul Ecol 43:53-62

Ruttner F (1966) The life and flight activity of drones. Bee World 47:93-100

Ruttner F (1988) Biogeography and taxonomy of honeybees. Springer Verlag, Berlin, Heidelberg, New York 
Ruttner H, Ruttner F (1966) Untersuchungen über die Flugaktivität und das Paarungsverhalten der Drohnen. 3. Flugweite und Flugrichtung der Drohnen. Z Bienenforsch 8:332-354

Ruttner F, Ruttner H (1972) Untersuchungen über die Flugaktivität und das Paarungsverhalten der Drohnen. V. Drohnensammelplätze und Paarungsdistanz. Apidologie 3:203-232

Schneider SS, DeGrandi-Hoffman G, Smith DR (2004) The African honey bee: factors contributing to a successful biological invasion. Annu Rev Entomol 49:351-376

Seeley TD (1985) Honeybee ecology. Princeton University Press, Princeton

Solignac M, Vautrin D, Loiseau A et al (2003) Five hundred and fifty microsatellite markers for the study of the honeybee (Apis mellifera). Mol Ecol Notes 3:307-311

Statistisches Bundesamt Deutschland (2005) Umwelt-Bodenflächen nach Art der tatsächlichen Nutzung. http://www.destatis.de./basis/d/umw/ugrtab7.php. Cited 27 Sept 2006

Taylor OR, Rowell GA (1987) Drone abundance, queen flight distance and the neutral mating model for the honey bee, Apis mellifera. In: Needham GR, Page RE, DelfinadoBaker M, Bowman CE (eds) Africanized bees and bee mites. Ellis Hoorwood, Chichester, pp 173-183

Walsh PS, Metzger DA, Higuchi R (1991) Chelex 100@ as a medium for simple extraction of DNA for PCR-based typing from forensic material. Biotechniques 10:506513

Wang J (2004) Sibship reconstruction from genetic data with typing errors. Genetics 166:1963-1979 
Weir BS, Cockerham CC (1984) Estimating F-statistics for the analysis of population structure. Evolution 38:1358-1370

Williams JL (1987) Wind-directed pheromone trap for drone honey bees (Hymenoptera: Apidae). J Econ Entomol 80:532-536 